\title{
Experimental Study on Strengthening of Steel Structures with Fiber Reinforced Plastic
}

\author{
Chensong Dong ${ }^{1, a}$ \\ ${ }^{1}$ Department of Mechanical Engineering, Curtin University of Technology, GPO Box U1987, Perth, \\ WA 6845, Australia \\ ac.dong@curtin.edu.au
}

Keywords: FRP; steel; strengthening

\begin{abstract}
An experimental study on the strengthening of steel structures with FRP (Fiber Reinforced Plastic) is presented in this paper. Test coupons were prepared by applying FRP patches on both sides of steel coupons. Standard tensile tests were conducted to the test coupons. Two types of CFRP (Carbon Fiber Reinforced Plastic) and one type of GFRP (Glass Fiber Reinforced Plastic) were studied. The load and strain data were recorded, and the stiffness and strength were derived. The results show that CFRP provides better strengthening than GFRP, but there is no significant difference between PAN graphite/epoxy and pitch graphite/epoxy laminates.
\end{abstract}

\section{Introduction}

Steel structures such as bridges, off-shore platforms, large mining equipment and buildings need retrofitting. The conventional method of repairing or strengthening steel structures is to cut out and replace plating, or to attach external steel plates. This requires shut down the structure being repaired and thus time-consuming and costly. An attractive alternative method is to use FRP.

Literature survey shows that there is a great potential for CFRP to be used in the retrofitting of steel structures. However, many issues need to be resolved before this advanced material can be fully utilized to provide confident retrofitting of existing structures [1].

An experimental study on strengthening steel plates with FRP is presented in this paper. Test coupons were prepared by applying FRP patches on both sides of steel coupons. Standard tensile tests were conducted to the test coupons. Two types of CFRP and one type of GFRP were chosen to be studied. The load and strain data were recorded, and the stiffness and strength were derived. The stress was also studied by finite element analysis (FEA).

\section{Experiments}

The test coupon used in this study is shown in Fig. 1. FRP patches were applied to both sides of a steel coupon. The FRP patches were prepared using ICC's Sitecure [2] technology. First, a steel coupon is grit blasted and primed. Second, the carbon fiber tape is placed according to the ICC design and a vacuum bag is placed over the top. Using vacuum ensures high fiber content and minimum void levels, and thus improves the strength and durability of repairs. Finally, a steam bag is applied to cure the prepreg. Steam at atmospheric pressure is always $100{ }^{\circ} \mathrm{C}$ and therefore the cure of the prepreg is extremely well controlled. After approximately 5 hours of "steaming" the resin has fully cured and the process materials are removed.

Two types of CFRP and one type of GFRP were chosen to be studied, as shown in Table 1. A total of 12 test coupons were prepared and standard tensile tests were conducted to each coupon. Strain gages were placed in the middle of the coupon on both sides to measure the strains of FRP patches. Another strain gage was placed on the side of the coupon to measure the strain of steel. The details of all experiments are shown in Table 2. In each experiment, the load and strain data were recorded. 


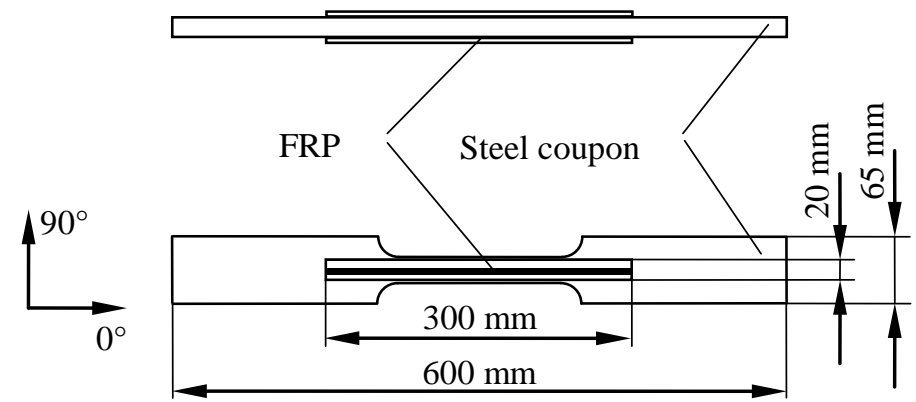

Fig. 1: Test coupon

Table 1: Materials used in experiments

\begin{tabular}{lll}
\hline Short ref & Reference & Description \\
\hline GL & EG UD 250 A & E glass unidirectional 250 gsm [52\% fiber by volume] \\
PA & PAN UD 500 A & PAN unidirectional 500 gsm [50\% fiber by volume] \\
PI & PIT UD 450 A & PITCH unidirectional 450 gsm [50\% fiber by volume] \\
\hline
\end{tabular}

Table 2: Experiments

\begin{tabular}{cccc}
\hline Experiment & Layup $\left.\mathrm{X}_{(\mathrm{x})}\right)^{\mathrm{x}} \ldots$ & Total Thickness $(\mathrm{mm})$ & Laminate Thickness $(\mathrm{mm})$ \\
\hline 1 & $\mathrm{GL}_{(2)}, \mathrm{PA}_{(4)}$ & 16 & 6 \\
2 & $\mathrm{GL}_{(2)} 0, \mathrm{PI}_{(4)}$ & 15 & 5 \\
3 & $\mathrm{GL}_{(2)}, \mathrm{PA}_{(4)}$ & 16 & 6 \\
4 & $\mathrm{GL}_{(2)}, \mathrm{PI}_{(4)}$ & 15 & 5 \\
5 & $\mathrm{GL}_{(2)}, \mathrm{PA}_{(4)}$ & 16 & 6 \\
6 & $\mathrm{GL}_{(2)}, \mathrm{PI}_{(4)}$ & 15 & 5 \\
7 & $\mathrm{GL}_{(4)}, \mathrm{PA}_{(4)}$ & 17.5 & 7.5 \\
8 & $\mathrm{GL}_{(4)}, \mathrm{PI}_{(4)}$ & 16.5 & 6.5 \\
9 & $\mathrm{GL}_{(2)}, \mathrm{PA}_{(8)}$ & 20.5 & 10.5 \\
10 & $\mathrm{GL}_{(2)}, \mathrm{PI}_{(8)}$ & 18.5 & 8.5 \\
11 & $\mathrm{GL}_{(4)}$ & 13 & 3 \\
12 & $\mathrm{GL}_{(2)}$ & 11.5 & 1.5 \\
\hline
\end{tabular}

\section{Results}

The strain-load curves of experiments 1 and 2 are shown in Fig. 2. It is seen that in the beginning of both curves, strain linearly increases with load. In experiment 1, after around $89 \mathrm{kN}$ the slope of FRP strains increases and similar trend occurs in experiment 2 at around $101 \mathrm{kN}$. This indicates failure starts to occur. The most significant failure mode was found to be steel and adhesive interface failure. This is in accordance with [1].
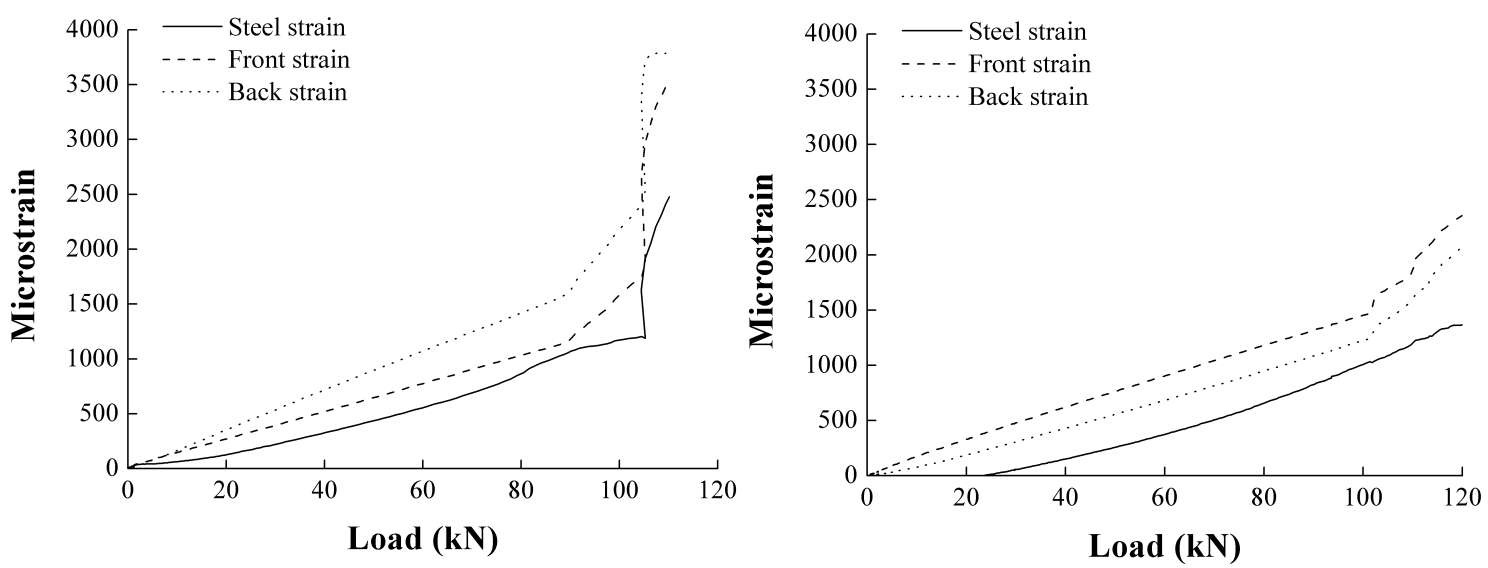

Fig. 2: Strain-load curve (Left: experiment 1; right: experiment 2)

The stress-strain curves of the elastic region of both experiments are shown in Fig. 3. The slope of a stress-strain curve is stiffness. It is seen that the stiffness of pitch graphite/epoxy patched steel 
coupons is higher than that of PAN graphite/epoxy patched ones. This is due to the higher stiffness of pitch graphite fibers than PAN graphite fibers.

The effective stiffness of a FRP patched steel coupon is given by the rule of mixture.

$$
E=\frac{E_{s} A_{s}+E_{g} A_{g}+E_{c} A_{c}}{A_{s}+A_{g}+A_{c}}
$$

where $E_{s}, E_{g}$, and $E_{c}$ are the stiffness of steel, GFRP, and CFRP, respectively; and $A_{s}, A_{g}$, and $A_{c}$ are the cross-sectional areas of steel, GFRP, and CFRP, respectively.

The stiffness calculated by Eq. (1) and from experiments is shown in Fig. 4. Good agreement is found except experiments 4 and 6. This discrepancy is due to some problems in these two experiments.

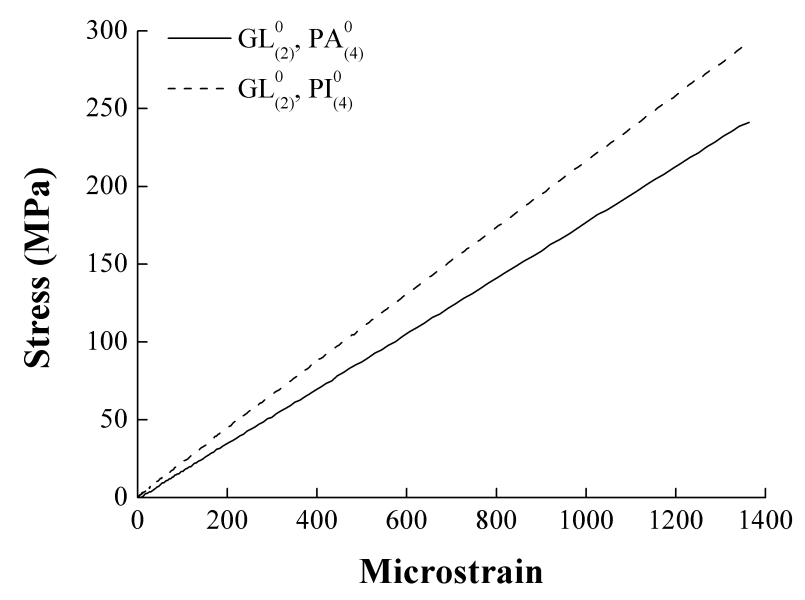

Fig. 3: Stress-strain curves of elastic region

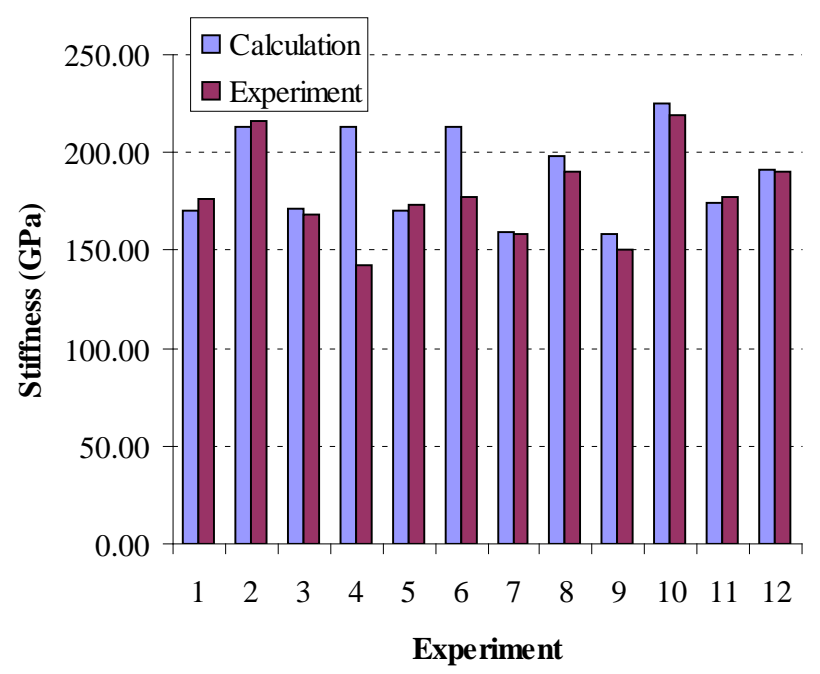

Fig. 4: Stiffness from calculation and experiments

The failure loads derived from the experiments are shown in Table 3. It is seen that CFRP provides better strengthening than GFRP, but there is no significant difference between PAN graphite/epoxy and pitch graphite/epoxy laminates.

\begin{tabular}{cc}
\multicolumn{2}{c}{ Table 3: Failure loads } \\
\hline Layup $\mathrm{X}_{(\mathrm{x})}{ }^{\mathrm{x}} \ldots$ & Failure load $(\mathrm{kN})$ \\
\hline $\mathrm{GL}_{(2)}, \mathrm{PA}_{(4)}{ }_{0}$ & 92 \\
$\mathrm{GL}_{(2)}, \mathrm{PI}_{(4)}$ & 101 \\
$\mathrm{GL}_{(4)}, \mathrm{PA}_{(4)}$ & 116 \\
$\mathrm{GL}_{(4)}, \mathrm{PI}_{(4)}$ & 104 \\
$\mathrm{GL}_{(2)}, \mathrm{PA}_{(8)}$ & 102 \\
$\mathrm{GL}_{(2)}, \mathrm{PI}_{(8)}$ & 99 \\
$\mathrm{GL}_{(4)}$ & 85 \\
$\mathrm{GL}_{(2)}$ & 85 \\
\hline
\end{tabular}

\section{Finite Element Analysis}

The stress under tension was analyzed by FEA using ANSYS. A load of $100 \mathrm{kN}$ was assumed. $\sigma_{x x}$ of $\mathrm{GL}_{(2)}{ }^{0}, \mathrm{PA}_{(4)}{ }^{0}$ and $\mathrm{GL}_{(2)}{ }^{0}, \mathrm{PI}_{(4)}{ }^{0}$ from FEA is shown in Fig. 5, and the distribution of $\sigma_{x x}$ along the through-thickness direction is shown in Fig. 6. It is seen that the stress is transferred from steel into FRP patches. The stress in steel is inversely proportional to the number of FRP layers. When pitch graphite/epoxy laminates are used, stress transferring is more effective, but the stress at the bondline is higher. 

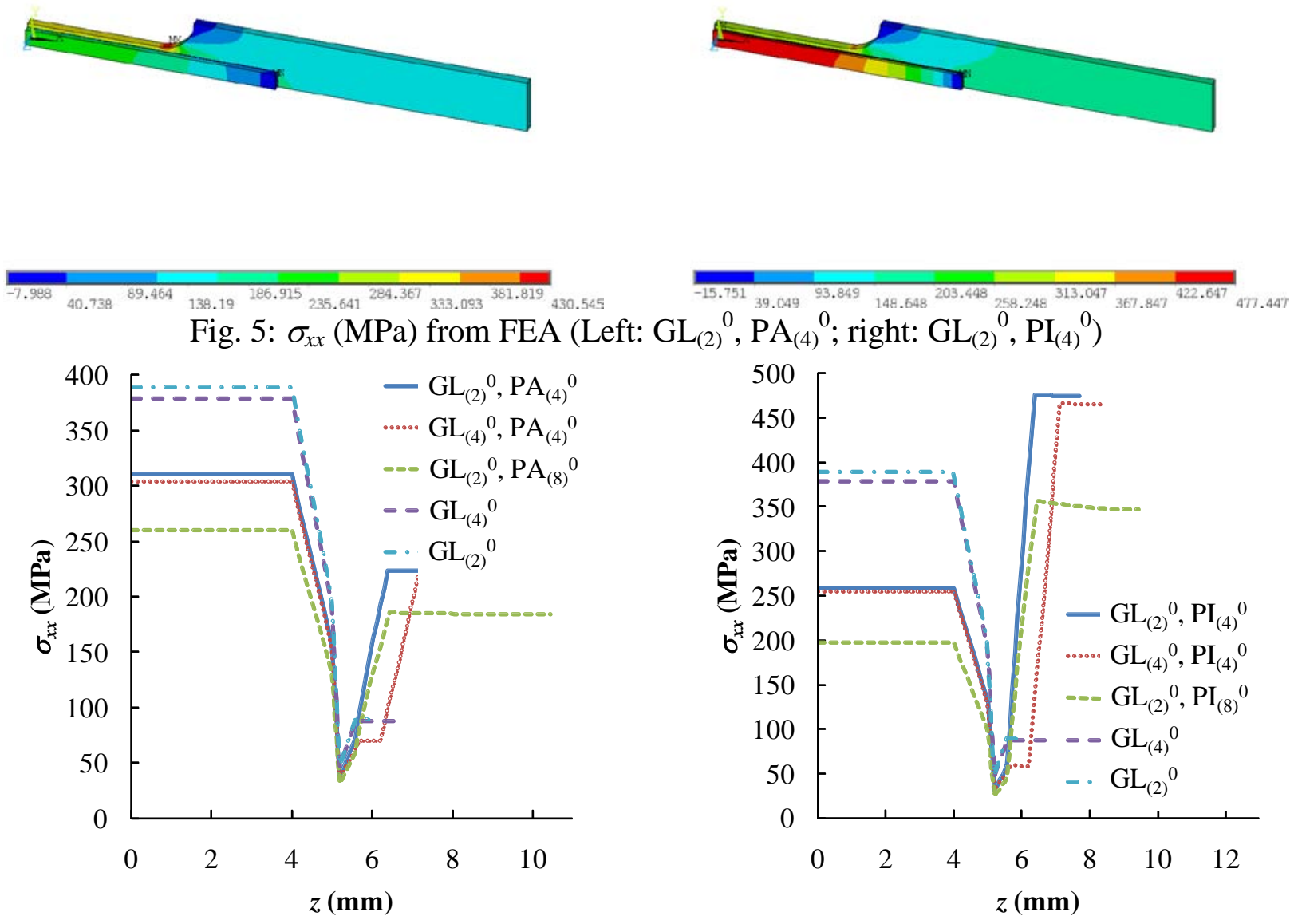

Fig. 5: $\sigma_{X X}(\mathrm{MPa})$ from FEA (Left: $\mathrm{GL}_{(2)}{ }^{0}, \mathrm{PA}_{(4)}{ }^{0}$; right: $\left.\mathrm{GL}_{(2)}{ }^{0}, \mathrm{PI}_{(4)}{ }^{0}\right)$

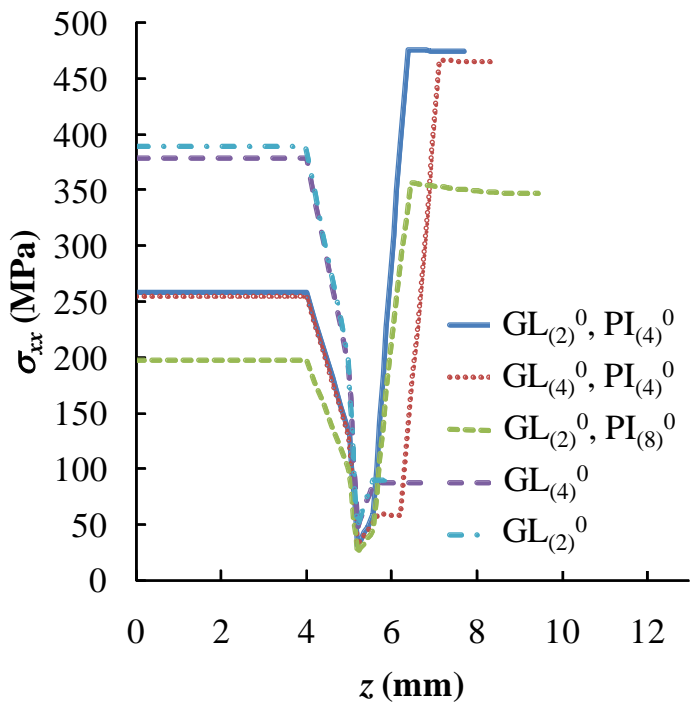

Fig. 6: $\sigma_{x x}$ distribution in through-thickness direction

\section{Conclusions}

An experimental study on the strengthening of steel structures with FRP is presented in this paper. Test coupons were prepared by applying FRP patches on both sides of steel coupons. Standard tensile tests were conducted to the test coupons. Two types of CFRP and one type of GFRP were studied. The load and strain data were recorded, and the stiffness and strength were derived.

As expected, CFRP provides better strengthening than GFRP, but there is no significant difference between PAN graphite/epoxy and pitch graphite/epoxy laminates.

Further study is needed to understand the effect of laminate thickness on strengthening.

\section{Acknowledgement}

The author thanks the support from Curtin Research Fellowship, and Mr. Colin McCullough and Dr. Laurie Walker of ICC (Industrial Catalyst Composites) for conducting the experiments.

\section{References}

[1] X.-L. Zhao and L. Zhang: Engineering Structures Vol. 29 (2007), p. 1808

[2] ICC: http://www.iceng.com.au 